\title{
Crossing Swords while Crossing Boundaries: Teaching Translation through Intermedial Translation Slams
}

\author{
Katerina GOULETI*and Vasiliki MISIOU**
}

\begin{abstract}
This paper discusses a cross-curricular translation project conducted within the framework of the literary translation and interlingual audiovisual translation (undergraduate) courses taught at the School of English, Aristotle University of Thessaloniki. The project was part of an optional module on literary translation and subtitling where students had to translate and subtitle into Greek some extracts of Margaret Atwood's The Handmaid's Tale and the relevant screenplay. The present paper thus explores the outcome of an online intermedial translation slam, a 'duel,' between student-translators and studentsubtitlers, who were asked to look at translation through another lens. Slamming is, thereby, viewed as a tool that can enhance the skills of literary translation and subtitling students, inviting them to participate in a thought-provoking process sharing and apposing insights, comparing and juxtaposing ideas, while being involved in an exchange of meaning and understanding. How does the interrelationship between different modes and media affect the choices literary translators and subtitlers make? What happens when a novel migrates into another language twice within the discursive spaces of intermedial dialogue? What are the benefits of engaging students in collaborative work and exposing them to simulated/real-life tasks? These are some of the questions that the paper will address and attempt to answer. The overarching goal is to examine the potential and advantages of integrating translation slams in a project-based approach to teaching and training literary translators and subtitlers within an academic framework.
\end{abstract}

Keywords: translation slam; literary translation; audiovisual translation; translator/subtitler training; project-based approach

\section{Introduction}

Teaching translation and training the translator have engaged considerable attention over the last decades, and a great number of studies have enhanced our understanding of key notions regarding the translation process, the role of the translator, and the need for actual translator training practice. From approaches and methods that focus purely on the process and/or product of translation to the rise of models which place emphasis on translators

\footnotetext{
* Academic and research fellow at Aristotle University of Thessaloniki. E-mail: agouleti@enl.auth.gr; ORCID ID: https://orcid.org/0000-0002-8546-4845.

${ }^{* *}$ Adjunct lecturer at Aristotle University of Thessaloniki.

E-mail: vmisiou@enl.auth.gr; ORCID ID: https://orcid.org/0000-0001-6985-2509.

(Received 21 April 2021; accepted 29 May 2021)
} 
themselves and how they approach their work, much has changed over the years largely affecting the framework within which translators work. With the ever-growing field of literary and audiovisual translation and their increasingly changing nature, the "move toward professionalizing" translation teaching (Peter 2020,12) is becoming all the more prominent. As Josep Marco rightly notes, translation pedagogy has turned its focus on "the student as learning subject rather than teaching object, highlight[ing] the importance of collaborative work ... and generally attempt[ing] to replicate real-world conditions in the classroom by means of (near-)authentic translation projects" $(2016,31)$. Having questioned and rejected long ago the static nature of knowledge within teacher-centered classrooms and being aware of the deficiencies of the "who'll take the next sentence" (WTNS) approach (Kiraly 2005, 1110), the syllabus design of our courses is to a great extent informed by the emerging pattern outlined above by Marco. This approach that draws from the Humanistic Language Teaching, the Communicative Approach, Cooperative Learning, and Social Constructivism ${ }^{1}$ (González Davies 2004, 12-15) has formed the basis for our own pedagogical approach to teaching literary translation and audiovisual translation, respectively - an approach that also falls within the principles of inductive teaching and learning, whereby learner-centered methods are applied via discussions, autonomous inquiries, collaborations, and enactment with real-life conditions (Prince and Felder 2006, 123).

Wishing, on the one hand, to make teaching more effective, and on the other, help students become more resourceful and develop not only the skills expected of a professional literary translator and subtitler but also their self-image as translators and subtitlers, we apply the project-based approach. By assuming the role of facilitators of knowledge, we support students and try to empower them, seeing them as "autonomous thinking individuals whose

\footnotetext{
${ }^{1}$ Under the Humanistic Language Teaching, students are viewed as subjects who can contribute to their own learning and competence and who do not passively receive knowledge from their teachers. Aligned with this view, group learning is preferred over independent learning (Arnold 1999; Brown 1971; González Davies 2002; Moskowitz 1978). The Communicative Approach brought to the fore the importance of meaning and pragmatics in students' attempt to communicate adequately in given situations (Brumfit and Johnson 1979; Candlin 1981; Hanvey 1992; Nunan 1993; Richards and Rodgers 2001). The Cooperative Learning approach places emphasis on creating an atmosphere where all students are actively involved in and are responsible for the final product. It is about building a positive teamwork environment in which students can develop their communicative and social skills and are able to improve their performance (Bassano and Christison 1994; Bennett, Rolheiser-Bennett, and Stevahn 1991; Holt 1993; Slavin 1990). Social Constructivism views students as the agents of the learning process with knowledge being constructed instead of transmitted. Teachers are guides, facilitators, a source of help and advice, guaranteeing group cohesion and collaboration (Benson and Voller 1997; Kiraly 2000; Williams 1999). All these approaches spotlight learner autonomy.
} 
transLogos 2021 Vol 4 Issue 1

Gouleti, Katerina, and Vasiliki Misiou, pp. 1-25

trans Dogos

A Translation Studies Journal

Crossing Swords while Crossing Boundaries: Teaching

Translation through Intermedial Translation Slams

(C) Diye Global Communications diye.com.tr|diye@diye.com.tr

capacity for meaning-making is no less valuable than that of the instructor" (Varney 2009, 29). However, while trying to respond to the needs and requirements of translation trainees fueled by rapidly evolving technological advances, one should remember that creativity and interpersonal skills are also important and need to be nurtured. Inspired by the question of whether we "can train creativity" (Kussmaul 1995, 22) and driven by the need to enrich the modules of TIS311 Literary Translation and TIS323 Interlingual Audiovisual Translation with student-engaging activities, we designed a student-led translation project that culminated in a live slam event.

The group of literary translation students were asked to translate excerpts of Margaret Atwood's The Handmaids Tale (1985); accordingly, the group of audiovisual translation students had to subtitle the equivalent extracts of Hulu's television adaptation (2017-) of the novel. At this point it needs to be noted that Atwood's novel was selected by applying a series of general criteria (Hurtado Albir 1995, 60; Nord 1991, 152-155), in line with the objectives of the project, but most importantly inspired by Paul Kussmaul's motivation factor; that is, we wanted students to "like the text . . . or at least . . like translating it" $(1995,51)$. It was vital that students be positively inclined towards their task. And it was a fortuitous coincidence that most of the students had either read the book or watched the film and all of them had heard of the story (largely thanks to Hulu). After the completion of their tasks, an online event was held where both groups had the chance to present and juxtapose their translated versions. The slam event was open to the public, welcoming questions and comments on the choices made, thus triggering fruitful discussions, feedback, and knowledge exchange. Students were offered the opportunity to witness the process of transformation and adaptation that takes place not only across languages and cultures but also across media. This way they were enabled to explore in practice how linguistic, cultural, semiotic, and medial topographies are intertwined and interwoven with one another.

From page to screen to page, a novel in motion allows students to comprehend that translation is never actually unidirectional, but rather several modes and various media interplay and contribute to the final outcome. Students realize that the very process of translation entails several crossings of boundaries between the verbal and (audio)visual realms and is shaped by an intricate and complex web of interrelationships. Based on the project carried out, this paper examines whether intermedial translation and slamming can be integrated and employed as pedagogical tools in the field of literary translator and subtitler training. It is firmly believed 
transLogos 2021 Vol 4 Issue 1

Gouleti, Katerina, and Vasiliki Misiou, pp. 1-25

trans Dogos

Crossing Swords while Crossing Boundaries: Teaching

A Translation Studies Journal

Translation through Intermedial Translation Slams

(C) Diye Global Communications diye.com.tr|diye@diye.com.tr

that intermedial and intermodal practices can make training more interactive, engaging students mentally and physically and leading them to a transformative and insightful learning experience that is further enhanced by collaborative endeavor.

\section{2. 'Intermediality' and 'Intersemiosis' at the Service of Translator Training}

The theoretical framework within which students were invited to explore the multifaceted role of the literary translator and subtitler and the interrelationships among the modes and media of meaning-making was informed by Roman Jakobson and his definition of "intersemiotic translation ${ }^{2}$ or transmutation" as "an interpretation of verbal signs by means of signs of nonverbal sign systems" $(1959,233)$. Drawing on Jakobson and centering focus on semiotic codes and their connections to each other, the transformative shifts witnessed when a written text turns into an audiovisual text are emphasized and so is the versatility required by literary translators and subtitlers alike. A novel that is translated into another linguistic and cultural system and is also adapted for a TV series is entangled in creative transmutation which involves rewording and reconstruction in different sign systems. Both the novel and the literary translator and subtitler are part of an interpretive universe characterized by negotiation, reworking, reinterpretation, adaptation(s), and sometimes also conflict.

By the time students were ready to embark on the project, they had also been introduced to the concepts of text, mode, and medium. Gunther Kress defines text as "any instance of communication in any mode or in any combination of modes, whether recorded or not" (2003, 48). Written and spoken language, visual images, sound, music, gesture, etc. are seen as communicative 'modes' of meaning (van Leeuwen 2005, 181). The term 'mode' is used by Gunther Kress and Theo van Leeuwen to refer to the "semiotic resources ${ }^{3}$ which allow the simultaneous realization of discourses and types of (inter)action" $(2001,21)$. Within this framework, students employed the term 'text' to refer to "message entities" as realized through writing, image, and speech (Kress 2003,37), while bearing in mind that multimodality impacts translation practices (Kaindl 2012; Dicerto 2018; O’ Sullivan and Jeffcote 2013). Students had

\footnotetext{
${ }^{2}$ Given that both student groups were assigned translation tasks from English into Greek and vice versa on a weekly basis, they had been introduced to Jakobson's triad and particularly his definition of "interlingual translation or translation proper" as "an interpretation of verbal signs by means of some other language" (1959, 233).

${ }^{3}$ Van Leeuwen defines 'resources' as 'the actions and artefacts we use to communicate, whether they are produced physiologically ... or by means of technologies" $(2005,3)$.
} 
transLogos 2021 Vol 4 Issue 1

Gouleti, Katerina, and Vasiliki Misiou, pp. 1-25

trans Dogos

Crossing Swords while Crossing Boundaries: Teaching

A Translation Studies Journal

Translation through Intermedial Translation Slams

(C) Diye Global Communications diye.com.tr|diye@diye.com.tr

also attended lectures on modes and media of communication, such as language itself, the book, and the screen and how they influence the process and product of literary translation and subtitling. Having familiarized themselves with literary conventions and having started to develop the necessary (audio)visual literacy skills that would allow them to navigate the text under discussion, they knew that when the "medium of book and mode of writing ... give way to the medium of screen and mode of image" (Kress 2003, 9), a number of changes are spawned that influence the choices made. They were well-aware of the fact that they would engage with different modes and media which would allow for greater interactivity. Quite importantly also, students realized that translators need to be(come) multimodally literate and be able to sustain such literacy (Misiou 2020, 261).

Novel writing and screenwriting create narrative by employing different methods that are related to differences in mode (written language, spoken language, image, sound) and medium. Thus, literary translators and subtitlers have to apply different skills to recreate narrative. Both prose fiction and literary adaptation and accordingly literary translation and audiovisual translation have their own idiosyncrasies, potentialities, limits, and constraints. For the purposes of the slam project, the term "intermedial translation" has been used, drawing both on Mieke Bal and Joanne Morra who define it as "translating across media" $(2007,7)$ and on Klaus Kaindl who builds on it underscoring that it is a type of translation "across media barriers, which can also be realized intraculturally and transculturally" $(2012,262)$. For Bal and Morra, to 'translate across' is identified with work "within discourses and practices of intertextuality, intersemiotics and interdisciplinarity, which can lead to movements across genres, media, bodies of knowledge and subjects" $(2007,7)$. Taking the above into consideration, it was imperative that both literary translation students and audiovisual translation students understand that this project, full of diverse possibilities and stimuli, would lead them to different reading and interpretative paths. The conflation of modes and the dynamics of media (from print to visual and multimedia) invited students to explore how intermediality and multimodality affect the process of translation and to focus not only on verbal signs but also on the challenges that arise from nonverbal meaning-making.

Students attending the two translation courses were aware that "what is expressed in language through the choice between different word classes and clause structures, may, in visual communication, be expressed through the choice between . . . different compositional structures" (Kress and van Leeuwen [1996] 2006, 2). This influenced their very understanding 
transLogos 2021 Vol 4 Issue 1

Gouleti, Katerina, and Vasiliki Misiou, pp. 1-25

transDogos

Crossing Swords while Crossing Boundaries: Teaching

A Translation Studies Journal

Translation through Intermedial Translation Slams

(C) Diye Global Communications diye.com.tr|diye@diye.com.tr

of the process of translation itself. Within a context of intermedial and multimodal possibilities, translation can be seen as the "centrifugal [sic] practice of text," in the words of Clive Scott, who believes that "the text is constantly in search of itself; . . that it has yet to fulfill itself, in paralinguistic realizations, in synesthetizations; that it does not own its literariness, but that this literariness is unstable, continually reinventable, always at the text's widening periphery." That is, through (the) process(es) of translation, the text can be transformed into "multiple versions of itself, not just interpretations of its meaning, but performances of the experience of reading it; and as the ST proliferates performatively, so it becomes increasingly synesthetic" (Scott 2010, 155). Hence, the emergence of two different translation products was hardly surprising due, on the one hand, to the diverse strategies employed, and on the other, to the function(s) of intermedial features. The practices adopted by both groups in light of the conventions of literary translation and audiovisual translation led to certain (re)interpretations and transformations.

\section{Slam: Performing the Practice of Translating}

Slam is, dictionary-wise, defined as an act of violent closure, a forceful collision, or a severe blow. In our case, translation slams are not perceived as a practice of rivalry but as a practice that entails a bloodless duel with an armory of words and phrases. The goal of such slams is not a hateful battle over an ideally correct version of a source text (ST) that stems from the strategy(-ies) translators employ to support their work. Quite the opposite, participants come head-to-head to defend their translation choices and illustrate the plurality of different understandings and renderings of the same original piece in a healthily contestatory vein.

\subsection{From Poetry Slams to Translation Slams}

One can find the idea of a translation slam rooted in the poetry slam ${ }^{4}$ movement. Since its early days, and with the foundation later of the International Poetry Slam movement in 1987 (Baig 2014), slam poetry has been a particularly popular practice providing the space for performers to connect with their audience in a deeper, more authentic way and, also, articulate thoughts and emotions concisely using two of the most powerful communication tools, that is, voice and words. Poetry slams managed to engage wider, general audiences, and they were an

\footnotetext{
${ }^{4}$ The first poetry slam competition was held in Chicago, in 1983. Construction worker and poet Marc Smith started a poetry reading at a Chicago jazz club, the Get Me High Lounge, wishing to refresh poetry (readings).
} 
instant success. The very concept of slam — bringing poets(-performers) together, having a host 'arbitrate' the battle, inviting the audience to participate in a live context (and, why not, contribute to the work) - and its actual implementation allow for a new kind of reading and engagement with texts, challenging all parties involved and guiding them to go beyond their preconceptions while (re)considering, among other things, their perspectives on what texts are and do. Translation slams resemble poetry slams and "open mike readings" given they all reach a wider, diverse audience, they take place in a space that allows for public assembly and discourse, and they foster a sense of intimacy, respect, and close listening (Damon 1998).

The translation slam traces its roots back to an event that took place in 1999 at the first Blue Metropolis Montreal International Literary Festival in Canada (Olohan 2020, 81). Similar venues such as International Book Fairs and World Book Day live events have hosted several translation slams in Greece over the last decade. Most of them are organized by professional associations such as PEEMPIP ${ }^{5}$ or independent institutions with emphasis placed mostly on literary texts, ${ }^{6}$ i.e., Translation Slam on Spanish Literature (2015), Translation Slam on Italian Literature (2018), Queer Translation Slam (2018), Detective Fiction Translation Slam (2019). ${ }^{7}$ Two translators translate the same short ST into the same target language and submit it before the event. On the day of the slam, they present and discuss their versions with the help of a moderator before an audience. They offer insight into the choices made, and they come to recognize, in hindsight, other plausible alternative options. Commenting on translators participating in slams, Tim Parks underlines that far from being "just subjective" (2017), emerging differences, sometimes quite broad, reflect the different, individual experiences translators bring to the text. Translation slams thus can be quite informative, revealing, and engaging not only for the audience but also for translators themselves who are involved in exploring and reflecting upon different practices of translating.

\subsection{Bringing the Practice of Translation Slams to the Classroom}

The rationale behind the implementation of a translation project drawing on translation and poetry slams was based upon the learning gains for university students, in line with the

\footnotetext{
${ }^{5}$ Panhellenic Association of Professional Translators Graduates of the Ionian University, Greece.

${ }^{6}$ The focus of most translation slams held so far has been on literary texts (Olohan 2020, 81).

${ }^{7}$ A subtitling slam took place for the first time in Greece in 2017, at the Translation Festival, a sidebar event within the International Book Fair of Thessaloniki. That year, The Language Project, a non-profit organization that offers help to vulnerable social groups, organized the first interpreting slam.
} 
transLogos 2021 Vol 4 Issue 1

Gouleti, Katerina, and Vasiliki Misiou, pp. 1-25

trans Dogos

Crossing Swords while Crossing Boundaries: Teaching

A Translation Studies Journal

Translation through Intermedial Translation Slams

(C) Diye Global Communications diye.com.tr|diye@diye.com.tr

focus being centered on enhancing the practical aspect of the two courses. Whereas students are provided with feedback only by other students and their teacher during a usual presentation in the classroom, in a slam event they are asked questions and receive comments on the choices and decisions they self-consciously make by a wider audience. This further enhances their understanding of the process of translation and their role as translators, while it prompts them also to consider key issues regarding audience reception.

As in the case of traditional translation slams, two versions were juxtaposed in front of an audience with the project managers of the two groups moderating the event. The different renderings of the STs were simultaneously presented, followed by a session of debate and thought-provoking discussion. Undeniably, some deviations from the traditional modes of holding a translation slam were deemed necessary. Firstly, the translated versions were not the outcome of individual effort and aspiration but the result of team formations, well-structured tasks, and distinct member roles. Secondly, the ST versions did not consist of the exact same written text. Extracts from the novel were compared to the relevant sections of the screenplay and the respective scenes from the TV adaptation. Lastly, as far as the project's structure is concerned, the translation stage was accompanied by two extra stages: pre-translation research/discussion of both texts and post-translation analysis in the form of reflective reports on the students' overall experience. An added feature that differentiated this translation slam from the ones held outside the academic environment is the fact that it was organized, produced, and held entirely in a virtual environment.

As for the audience, it was not seen as a passive observer receiving the input delivered during the event; rather, all attendees were prompted to participate actively and express their opinions, comments, and thoughts. Tim Gutteridge asserts that "for a slam to really come to life, you need an audience that is engaged - and is willing to really question the translators' choices" (2018). We could not have asked for a more engaging audience. There were both students and scholars from several Greek universities and colleges and, equally importantly, professional literary translators and subtitlers who drew on personal experience, sharing knowledge and expertise and engaging in a dynamic interaction with the slammers. Given the event was promoted in social media, there were also attendees with no prior knowledge of either literary translation or audiovisual translation. Hence, the audience was quite heterogeneous from diverse backgrounds, offering a fascinating insight into the discussion taking place. A briefing session was held at the beginning of the event to inform the audience about the 
transLogos 2021 Vol 4 Issue 1

Gouleti, Katerina, and Vasiliki Misiou, pp. 1-25

trans Dogos

Crossing Swords while Crossing Boundaries: Teaching

A Translation Studies Journal

Translation through Intermedial Translation Slams

(C) Diye Global Communications diye.com.tr|diye@diye.com.tr

procedure of the slam. The interaction was twofold. All attendees could post comments and type their questions in the Q\&A section (chat) of the platform throughout the event. The project managers of the two groups (moderators) monitored the chat, making sure that slammers had the time needed to explain their choices and reply to questions posed by the audience. Attendees were also provided with the opportunity to directly address their/unanswered questions in the Q\&A session at the end of the event.

The creation of a stimulating, safe, and supportive environment along with the popularity of the novel and its TV adaptation were also conducive to interactive participation and audience engagement. Attendees occasionally overtly opted for one choice over another; however, they did not intend to 'correct' the target texts (TTs). They challenged some of the slammers' choices, offering alternative options and raising questions regarding the semantic and pragmatic aspects of meaning; and this, in turn, steered dialogue and led to an interesting and fruitful negotiation not only among slammers themselves but also between slammers and the audience. Slammers were thus allowed to reconsider (as we shall see below) some of the decisions made and explore whether the alternatives suggested were adequate and acceptable and whether they could improve the TT or not.

\section{The Handmaid's Tale in Motion: Translation Students in Action}

One of the first things that translation students learn is the importance of conducting research, not only before embarking on translating a text but also during the translation process. In this vein, and before throwing themselves into the assigned translation tasks, both groups deemed necessary to carry out in-depth research to better prepare and familiarize themselves with the material at hand. To this end, both the literary translation and audiovisual translation students set up their research teams each comprised of two members. The two teams explored the main themes of The Handmaid's Tale, defining characteristics of the dystopian genre, the postmodern techniques adopted by Atwood, the use of language and its symbolism, as well as the discursive forms employed. Additionally, they investigated the concept of historiographic metafiction, they examined Atwood's feminist positions and also (whether and) how feminist tradition is reflected in the novel, and they traced biblical and religious allusions. At the same time, emphasis was placed on how the important issues of gender, power, religion, culture, class, and race were illuminated by the narrative. Equally important was their research on 
interviews given by Atwood herself, newspaper articles, journal and scholarly papers that discuss and study her work, biographical references, and book reviews, anything considered important for acquiring deeper knowledge and understanding of her fiction and writing style. The social, cultural, and political context within which the novel was set and created was also analyzed. Thanks to research, students were allowed to realize that extratextual 'epitexts ${ }^{8}$ help the "reception for the text and a more pertinent reading to it" (Genette 1997, 2) and that all pieces of information within or outside the text are equally important.

As discussed above, the two groups adopted mainly similar research approaches. What was different, though, was the method of sharing the data collected. The literary translation research team created a folder that included research data files, information on specific resources, relevant links, and a report on primary and secondary sources. They then uploaded this folder and shared a Google Drive link that allowed anyone with access to it not only to view the content but also to edit it. This way, all members of the literary translation group (translators and proofreaders alike) could add the material that emerged during the process of translation and proofreading. Therefore, any edits within the folder were immediately seen by all members, enhancing their collaboration. The audiovisual translation research team, however, opted for another means of organizing and sharing data with the relevant parties. They prepared a detailed PowerPoint presentation that addressed key information with regard to the novel and the TV series. This file was intended to function as a multifaceted guide for the subtitlers and proofreaders and particularly those who had not read or watched the series before. Sharing this file in time added to the effectiveness of their collaboration and allowed the members of the research team to see whether they had met the needs of their colleagues and decide on next steps. Judging from the comments made by the latter, the PowerPoint presentation provided them with all necessary data and information and assisted them in subtitling the material under examination.

\footnotetext{
8 'Epitexts' (reviews, interviews, autocommentaries, author websites and essays, critical literary analyses, etc.) constitute along with 'peritexts' the 'paratext'; according to Gérard Genette, the 'epitext' is "any paratextual element not materially appended to the text within the same volume but circulating, as it were, freely, in a virtually limitless physical and social space" $(1997,344)$.
} 
transLogos 2021 Vol 4 Issue 1

Gouleti, Katerina, and Vasiliki Misiou, pp. 1-25

transDogos

Crossing Swords while Crossing Boundaries: Teaching

A Translation Studies Journal

Translation through Intermedial Translation Slams

(C) Diye Global Communications diye.com.tr|diye@diye.com.tr

\subsection{Designating Roles and Assigning Translation Tasks}

Given the high number of students enrolled in the two courses and knowing that they could not participate all in the translation project, we addressed a call for expression of interest. Forty-two students declared their wish to work on it, and this led initially to the formation of two groups. As instructors and organizers of the event, we prepared the material to be translated and subtitled, respectively, and we met with the members of the two groups to which we had assigned the role of project managers. Both literary translation and audiovisual translation tasks had to be carried out under specific time constraints (two weeks) which were co-decided. The workflows of translation and proofreading were also set up during this meeting. A style guide was distributed, along with files regarding the language conventions to be followed and the spatiotemporal limitation for the spotting of subtitles.

The aim was to create a setting simulating professional conditions in which all groupmembers could work collaboratively, enabled to develop and integrate their skills. The two groups were then further divided into teams of translators and proofreaders based on whether they had read the novel, watched the series, or both. At this point, it needs to be stressed that due to the COVID-19 pandemic quite many members of the literary translation group had to withdraw. This resulted in reshuffling the rest of the participants with some students performing the role of both the translator and the proofreader. Thankfully, the audiovisual translation group saw no such loss and the two roles were entirely separable; that is, there was the subtitling team and the proofreading team. The translators and proofreaders of the two groups addressed any question they had and/or discussed problems that emerged with the project managers, who were also in charge of submitting the final translation product before the event.

\subsection{The Slam Event}

Upon completion of the translation tasks, the project managers of the two groups coedited a presentation, pinpointing the key issues faced by their teams. They enriched the content of the presentation with screenshots of their work, video extracts, and visually juxtaposed renderings. This multimodal presentation was sent to the two instructors well in advance of the slam day. The slam took place on December 21, 2020 and was streamed live via Zoom. 
transLogos 2021 Vol 4 Issue 1

Gouleti, Katerina, and Vasiliki Misiou, pp. 1-25

transDogos

A Translation Studies Journal

Crossing Swords while Crossing Boundaries: Teaching

Translation through Intermedial Translation Slams

(C) Diye Global Communications diye.com.tr|diye@diye.com.tr

4.2.1 General Remarks. Students were well-aware of the fact that the challenges posed by literary translation and audiovisual translation demanded they be not only bilingual but also bicultural (if not multicultural in today's world). Some common difficulties that arise when dealing with either of these two types of translation concern culturally specific expressions, intertextual references, wordplay, idioms, proverbs, newly coined words, and humor.

The literary translation group firstly shared their basic concerns regarding the idiosyncrasies of their translation mode. Literary texts feature distinctive lexical and stylistic characteristics that are umbilically tied to the unique writing style of their authors. Issues related to alliteration, consonance, and assonance, among other literary devices, which add to the musicality of a literary text, took precedence. Literary translation students know they need not only focus on the semantic aspect of meaning but also explore the context of utterances ${ }^{9}$ and the conditions in which they are used - that is, place emphasis on the pragmatic aspect of meaning (House 2015, 21) as well. They thus attempted to render accurately the messages and the aesthetic values of the original, while allowing, at the same time, readers to dive deep into the intellectual and imaginative depths of the ST by recreating the situations, emotions, and understandings set forth by the author. Atwood's use of long sentences, asyndeton, diction, and certain punctuation marks were also addressed by the members of the literary translation group and discussed during the slam. Another issue raised was their decision to make limited use of footnotes and only when information could not be integrated smoothly into the text. Nonetheless, it needs to be underlined that this was an affordance that could not be used by the audiovisual translation students.

The latter discussed the concerns raised by their translation mode focusing mostly on the restrictions regarding the number of characters per line and per second. To address these challenges, they had to find ways to manipulate in two dimensions: the degree of condensations they had to apply to the original screenplay and the speed at which the subtitles needed to be presented (Díaz Cintas and Remael 2007, 107). They further expanded on the constraints imposed by the concurrent display of both the ST, accessible to the audience via the original audio input, and the TT. This cohabitation of the two texts and the immediacy of their reception

\footnotetext{
${ }^{9}$ In the words of Jenny Thomas, "meaning is not something which is inherent in the words alone, nor is produced by the speaker alone, nor by the hearer alone. Making meaning is a dynamic process, involving the negotiation of meaning between speaker and hearer, the context of utterance (physical, social and linguistic) and the meaning potential of an utterance" $(1995,22)$.
} 
are unique to this translation mode and a focal point of the audiovisual translators' remarks. Apart from the aural encodings, visual representations are brought into the equation, composing the multisemiotic nature of the audiovisual product as a different semiotic system. Student subtitlers took this parameter into account, and their comments revolved a lot around the cases where the provision of information via a visual channel hindered or facilitated their subtitling choices. The omnipresence of the image was illustrated by two short video extracts of scenes where no verbal content was conveyed in the TV series; however, the same scenes were built up in passages consisting of several lines in the extracts from the book. To visually depict this intermedial blending, they had the literary TT superimposed as scrolling text on the moving image (fig. 1).

Figure 1. Literary translation texts superimposed on The Handmaid's Tale video extracts
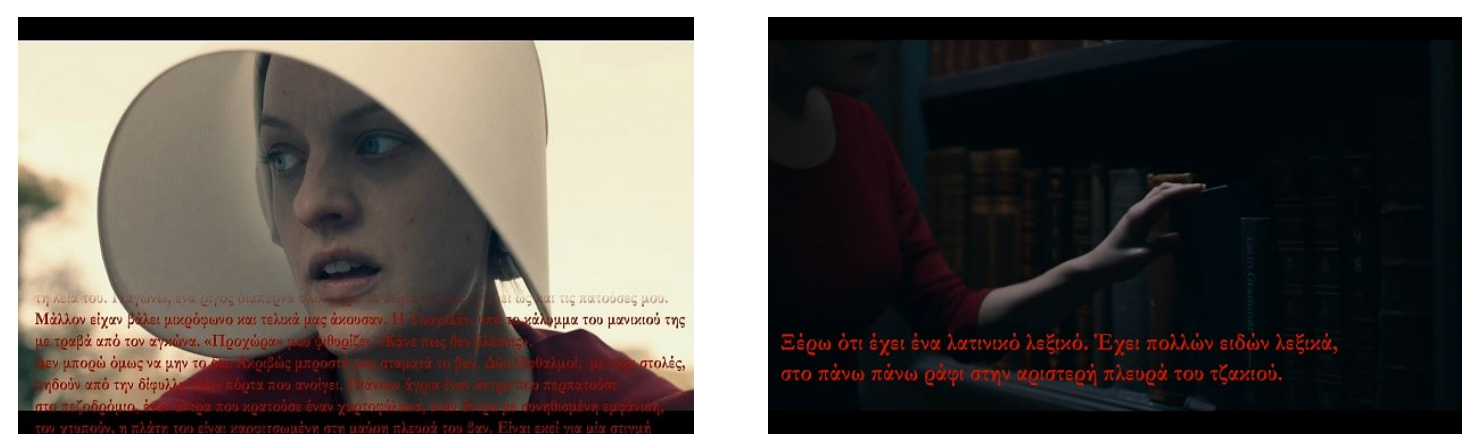

4.2.2 Instances of Orality. Having prioritized the need to offer a text that 'sounded' natural, both literary translation and subtitling students had to decide on whether they would reproduce authentic forms of discourse or not. Literary translation students considered it necessary to maintain in the target literary text the features of orality embedded in the ST. They wished to recreate the literary effect generated by the language Atwood used and the stylistic techniques she employed. Hence, readers of the students' TT encountered (i) ejaculations and

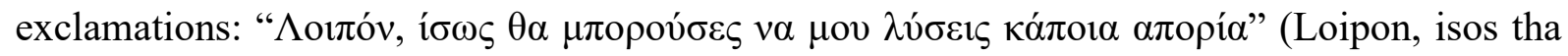
borouses na mou lyseis kapoia aporia) "Well, maybe you could tell me something I've been

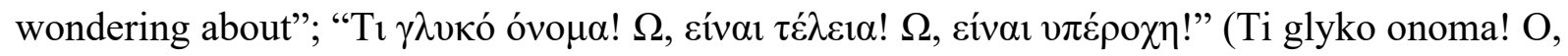
einai teleia! O, einai yperochi!) "What a sweet name! Oh, she’s perfect! Oh, she’s wonderful!,"

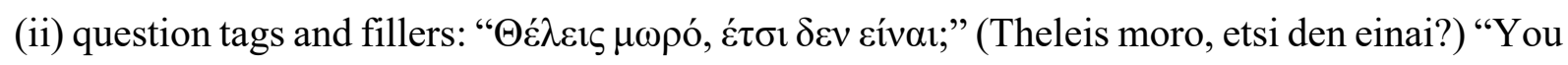


transLogos 2021 Vol 4 Issue 1

Gouleti, Katerina, and Vasiliki Misiou, pp. 1-25

transDogos

A Translation Studies Journal

Crossing Swords while Crossing Boundaries: Teaching

Translation through Intermedial Translation Slams

(C) Diye Global Communications diye.com.tr|diye@diye.com.tr

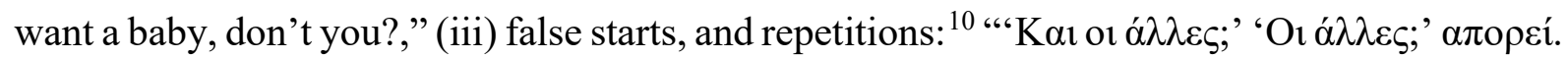

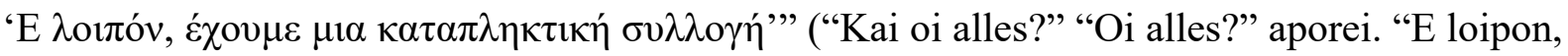
echoume mia katapliktiki syllogi") "And the others?" "The others?" he says. "Well, we have quite a collection." Such choices allowed the characters' voices to be heard highly influencing reading experience.

When it comes to subtitling, though, film dialogue, originally meant to be spoken, must be transferred into writing in the form of subtitles. The transition from one mode to another usually leads to instances of spoken discourse ending up simplified and/or cleaned-up and, in certain cases, partially or fully omitted. Viewers of the interlingually subtitled extracts see instances of orality, such as spontaneous speech or rhetorical discourse, disappear during this transition due to the limitation regarding the number of characters per line and the existence of pictorial elements that compensate for the loss of oral markers. There was a sentence, though, that truly was the source of heated debate. In one of Offred's regular visits to the gynecologist, the latter offers to impregnate her and says: "It'd only take a minute, honey" (in the screenplay: "It'll only take a few minutes, honey"). The subtitling group decided to omit the word

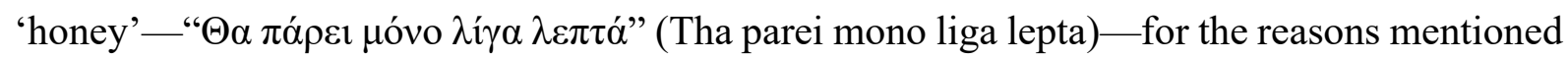
above. However, the audience expressed its discontent for this omission, due to the power relations and ingrained roles within the Gileadean society, and encouraged the members of the group to reconsider their stance. Having been exposed to many different views, the latter carefully reviewed their decision and stated that they should have translated the word.

The literary translation group could not have opted for omission given, among other things, that 'honey' is repeated in the two sentences that follow immediately after this one.

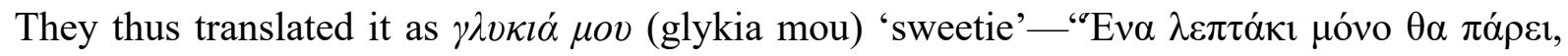
$\gamma \lambda v \kappa i \alpha ́ \alpha$ ov" (Ena leptaki mono tha parei, glykia mou)—a choice that led to several questions from the audience, which, along with the subtitling students, questioned its adequacy. Whereas they endorsed the choice of $\lambda \varepsilon \pi \tau \alpha \dot{\alpha} \kappa l$ (leptaki) as a diminutive of 'minute' and they seemed to agree with the slammers' wish to show the doctor was patronizing Offred, they strongly disagreed with the choice of $\gamma \lambda v \kappa i \alpha$ $\mu o v$. Some attendees claimed that Atwood deliberately uses sexist language here and suggested they use $\kappa o v ́ \kappa \lambda \alpha \mu o v$ (koukla mou) instead, which is a term

\footnotetext{
${ }^{10}$ According to Carolina P. Amador Moreno and Ana Nunes (2009), readers recognize these oral features, among others, as authentic traits of talk. See also in Amador Moreno and McCafferty (2011, 3-4).
} 
transLogos 2021 Vol 4 Issue 1

Gouleti, Katerina, and Vasiliki Misiou, pp. 1-25

transDogos

A Translation Studies Journal

Crossing Swords while Crossing Boundaries: Teaching

Translation through Intermedial Translation Slams

(C) Diye Global Communications diye.com.tr|diye@diye.com.tr

of endearment in Greek-literally it means 'my doll,' (affectionate) 'sweetheart' — but it also has negative connotations, and it can be loaded with irony. It was then that slammers emphasized their choice was made on this ground; however, having acknowledged that the audience was not enabled to interpret it this way, they offered another alternative, $\gamma \lambda \dot{v} \kappa \alpha$ (glyka) 'darling,' which was accepted by all as appropriate to the context.

4.2.3 Lexical Choices. By and large, the two groups faced similar challenges with regard to the rendering of certain lexical items and phrases, namely the translation of a) the Handmaids' names (Offred, Ofglen, etc.), b) fictitious portmanteau words, such as the word 'particicution' (a portmanteau of the words 'participation' and 'execution') which refers to a type of execution or 'salvaging' executed by a group of Handmaids, c) Latin phrases such as the phrase Nolite te bastardes carborundorum which Atwood herself translated at some point in the novel as "Don't let the bastards grind you down" and which is very important to the development of the plot, d) expressions and proverbs that allude to biblical quotes, such as the expressions "No rest for the weary" and "Chickens always come home to roost," e) culturally loaded toponyms, such as the 'Hudson.' Being familiar with the text typology introduced by Katharina Reiss ([1977] 1989, 108-109), who drew on Karl Bühler's concept of "language functions"11 (1934), and having identified that the ST belongs to the 'expressive' type, ${ }^{12}$ both literary translation and subtitling students focused on the aesthetic dimension of the ST as well. They paid attention to stylistic variation (placing emphasis on sound, rhythm, punctuation), and they tried to communicate and evoke the feelings and thoughts of the characters through appropriate word choice and use of imagery and descriptive language, thus recreating the tone and mood of the original.

Among the choices that generated an engaging discussion between the slammers and the audience was the translation of the Handmaids' names. Atwood created their names by the addition of the prefix 'Of-' to the first name of the man who owns them; therefore, Offred is Of-Fred, the reproductive handmaid of Fred. The Handmaids' names symbolize their lack of status, and, perhaps more importantly, their lack of individuality and identity, their facelessness. Both groups decided to follow the formation of the equivalent ST names; that is, they rendered

\footnotetext{
${ }^{11}$ Bühler (1934) identified three communicative functions: the informative, the expressive, and the appellative function.

${ }^{12}$ In an expressive text, a translation "transmits a direct impression of the artistic form of the conceptual content." According to Reiss, authors consciously decide on the "means of verbalization" and they structure the text "doubly: first on the syntactic-semantic level, and second on the level of artistic organization" (Reiss [1977] 1989, 109).
} 
transLogos 2021 Vol 4 Issue 1

Gouleti, Katerina, and Vasiliki Misiou, pp. 1-25

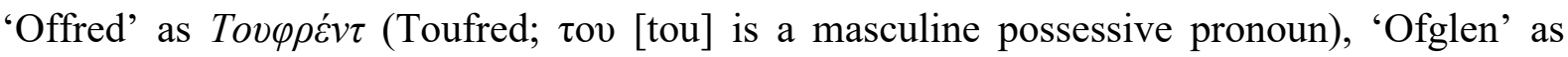

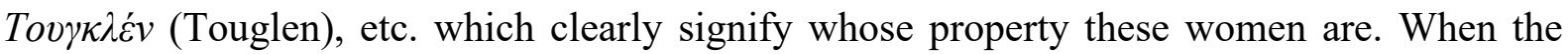
audience asked whether this was the only option available, slammers from both groups commented on two possible renderings - as they stressed, they could either transliterate them as a single word, which was what they did, or render them as two-word names (hyphenated $[T o v-\Phi \rho \varepsilon v \tau]$ or not $[\operatorname{Tov} \Phi \rho \varepsilon v \tau])$. In their words, if they opted for the second choice, they would capitalize the first letter of the man's name to emphasize that the Handmaids were a mere possession, which was clearly reflected in language use. They decided on the first option because they wanted to achieve the effect of a real name and stress that these were now the only names women could use.

An interesting debate was also sparked about the two groups' translation of the Latin phrase Nolite te bastardes carborundorum, focused on Atwood's rendering, given they adopted a different approach. Literary translation students employed the equivalent Greek word for the word 'bastards' — $\mu \pi \alpha \dot{\alpha} \sigma \tau \alpha \rho \delta \alpha$ (bastarda) - aiming to preserve the sound of the word and achieve equivalent effect, and they rendered the phrasal verb 'grind (somebody) down' as $\sigma \varepsilon \pi \alpha \tau \alpha \dot{v \varepsilon}$ $\kappa \alpha ́ \tau \omega$ (se patane kato) which translates back into 'step on somebody.' As they explained, they considered it important to preserve the meaning of 'down' ( $\kappa \alpha \dot{\tau} \omega$ kato), which would enable readers to visualize the action, and underscore, at the same time, the disempowerment of women who were no longer able to stand up for themselves and resist. The audience and the slammers from the subtitling group contested the decisions taken and invited the literary translation students to discuss their choice of the neuter gender of the word $\mu \pi \alpha \dot{\sigma} \sigma \alpha \rho \delta o \varsigma$ (bastardos) over the more appropriate, as they noted, masculine one $\mu \pi \alpha \dot{\sigma} \tau \alpha \rho \delta o \imath$ (bastardoi) for women's enemies were clearly men. In between the "yes, but..." and the "no, but..." part of the negotiation there was space for the challenged slammers to defend their choice by explaining that this phrase was used by Fred (Commander Waterford) when he was a schoolboy and they wanted to add the element of language used by children (also a neuter word in Greek, in which there is gender agreement between nouns and adjectives). Thus, they said they would not change it.

On the other hand, the subtitling group rendered 'bastards' as $\kappa \alpha \theta \dot{\alpha} \rho \mu \alpha \tau \alpha$ (katharmata) in Greek, which is also offensive and characterizes a dishonest and unethical person. Considering that the word is uttered (and thus heard by viewers), they felt the need to tone it down a bit in its written form and strengthen the meaning of the phrase by using the verb 
transLogos 2021 Vol 4 Issue 1

Gouleti, Katerina, and Vasiliki Misiou, pp. 1-25

trans Dogos

A Translation Studies Journal

Crossing Swords while Crossing Boundaries: Teaching

Translation through Intermedial Translation Slams

(C) Diye Global Communications diye.com.tr|diye@diye.com.tr

$\tau \sigma \alpha \kappa i \zeta \omega$ (tsakizo) to render the phrasal verb 'grind somebody down.' The choice of this verb was hailed by all attendees. In Greek, $\tau \sigma \alpha \kappa i \zeta \omega$ literally means to break, hit violently, smash somebody/something and figuratively it means to cause mental pain to somebody, to destroy somebody's feeling of determination. Hence, they managed to convey the tone and reproduce the effect of the original, while using a shorter word and respecting technical conventions. The literary translation students noted that they would willingly adopt this word as well, as it creates imagery and could appeal to the senses of readers.

4.2.4 Swear Words. Though there was no intention to mitigate any swear words, ${ }^{13}$ the literary translation group encountered few instances of swearing in the passages they had to translate. Thus, it was not a problem they had to deal with. On the contrary, the TV series' original screenplay included multiple such instances. Although the program was classified as K16, that is, it was not recommended for viewers under sixteen, subtitlers leant towards toning down swear words instead of omitting them and they looked for equivalent words in the target language, appropriate to the context, only when deemed necessary.

Emotionally charged words such as 'fuck' and 'shit' were frequently present in the original screenplay, triggering a wide range of emotions from indignation, disgust, and contempt to surprise, delight, and enthusiasm. Indicative examples can be drawn from casual discussions among friends, during flashbacks to the protagonists' former life. Phrases like "Sorry fucking Uber," "A fucking moron," "Shitty cell phone reception," and "Holy shit" were

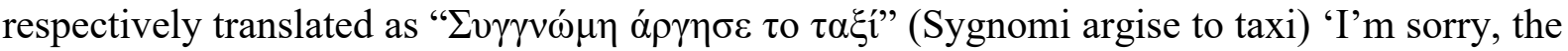

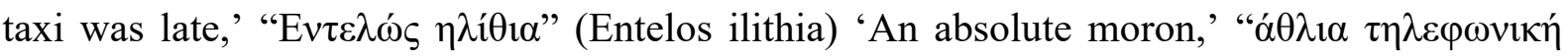

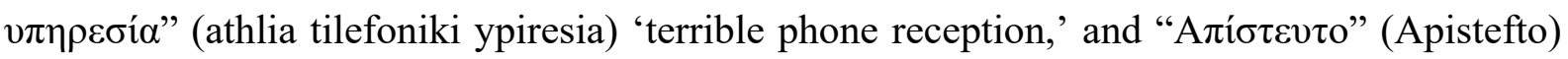
'Amazing.' As the subtitling slammers argued, directly translating these phrases would not necessarily render the intended meaning. On the other hand, they were assertive in their decision to retain the intensity of swear words when these clearly impinged on the plot and character representation, ultimately affecting the message. For instance, the phrase "Fucking sluts. Get the fuck out of here," an appalling insult hurled at the female protagonists, was

\footnotetext{
${ }^{13}$ For the purposes of this paper, we draw on Tony McEnery's study of swearing and his definition of 'bad language' as "any word or phrase which, when used in what one might call polite conversation, is likely to cause offence" (2006, 1-2).
} 


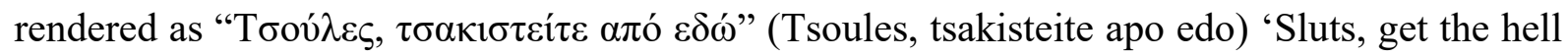
out of here.'

Taking into consideration that swear words are content-related and content-restricted (Jay 1992, 13), the subtitling group examined several factors before deciding on translating them or not. In the discussion that emerged, they managed to underscore the righteousness of their choices and persuade the audience to agree with their views. Following Richard A. Spears, the age, sex, and point of view (1998, ix) of the subtitlers may have also played a role in the decisions made. A similar view is expressed by Jorge Díaz Cintas and Aline Remael, who maintain that subtitlers may sometimes "self-censor" swear words based on their personal views of what is appropriate or not for the target culture and taking into account the channel of communication $(2007,198)$. Working on the subtitles of a TV series automatically means addressing and trying to meet the expectations of a wider and 'more heterogeneous' target audience compared to that of other media (24). Hence, regardless of whether subtitlers and translators alike consider that a given swear word or expression is important and it should be rendered in the target culture equivalent, they still need to respect the prevailing norms and sensibilities of the target culture. Especially when these words and/or expressions will appear on the TV screen.

\section{Discussion}

The translation project that led to the slam event and is described in this paper combined the traditional approach to translator education and the project-based approach. Both courses (TIS311 Literary Translation and TIS323 Interlingual Audiovisual Translation) actually draw on these two approaches; they start with an introduction to the fundamentals, a general overview of literary and audiovisual translation, then have students exposed to the conventions, linguistic and technical dimensions, and, when deemed appropriate (based on the stage of training), ${ }^{14}$ move on to hands-on tasks aimed at developing students' literary translation/subtitling skills that enable them to venture beyond their comfort zone(s), to undertake autonomous work and feel empowered (Kiraly 2005, 2012b; Marco 2016).

\footnotetext{
${ }^{14}$ Dorothy Kelly maintains that these two major approaches are "complementary, and that the difference between them is simply a question of level/stage of training, that is of sequencing. In this respect, rather than two opposing paradigms, they are perhaps better understood as the two extremes of a cline related to student autonomy" (2005, 116).
} 
In the present case study, when students were ready, they were invited to undertake collaborative work and embark on an authentic project, the translation slam event. The benefits of collaborative learning and teamwork were highlighted by translators, subtitlers, and proofreaders alike. Drawing on the concept of synergy, Maria González Davies asserts that

the whole is not only the sum of the parts, i.e., positive team work - in which each member of the team strives towards attaining the best collective performance - can contribute to reduce peer pressure, improve communicative and social skills, bridge linguistic and cultural diversity, and increase group cohesion, thus resulting in more effective learning. $(2004,13)$

Students cherished the interaction with the other literary translators and subtitlers of their group, they shared concerns, exchanged ideas, and expressed different viewpoints, all conducted within a pedagogical framework characterized by conviviality, support, and creativity. They interacted and negotiated in ways that were meaningful to them. They had to undertake problem-solving initiatives and manage time wisely to respect the submission deadline set. They used various means of communication to contact each other, ranging from social media platforms to the Moodle forum. They fulfilled the duties arising from the distinct but mutually respected roles assigned to them, working on a project that enhanced their performance, fostered their self-reliance, and allowed them to meet individual and collective needs, while getting experience of the various stages involved in the literary translation and subtitling workflow. Both instructors were tactfully present, offering guidance when needed and acting as mediators and facilitators of learning. Students' collaboration was remarkably smooth from beginning to end, and there was no need for the instructors to intervene. ${ }^{15}$ All roles had been precisely allocated early enough, and the responsibilities of each student were clearly defined. The decision to have students who assumed the role of project manager in each group proved also beneficial. Mutual trust and respect characterized the relationship among parties, and all contributed equally to the project. They shared responsibilities and solved problems together.

The combined approach applied may have proved challenging and more demanding in terms of workload and time requirement, but it was far more engaging and appealing to students. Teaching online (due to the pandemic) literary and audiovisual translation theory and

\footnotetext{
${ }^{15}$ Marco stresses that sometimes "the teacher cannot be a mere facilitator of learning but is forced to make some radical interventions in the face of obvious mistakes and the need to ensure continuity of collaboration" $(2016,41)$ as not all students are "ready to assume an expert role" (39).
} 
practice in the form of teacher-centered lectures alone could potentially make students lose interest, lower their motivation, and lead to their disengagement. When students are exposed to simulated and/or real-life tasks (situated learning), ${ }^{16}$ in the present case they were engaged in a translation slam, they are encouraged to think and act like professionals and reflect on their work. What is also important is the fact that a large percentage of the intended audience attending the online translation slam event was informed regarding the particularities of the two types of translation and the several strategies involved in the process. This further urged students to use metalanguage when describing their methodology, making specific references to the theoretical approaches they drew on, and the literary translation and subtitling techniques they adopted. Also, students put more transferable skills into practice on the day of the translation slam, as they had to argue and defend their choices in dialogue with one another and the audience. There were similarities and differences to comment on, which reflected the codes and conventions of each mode and were the source of interesting discussion that enabled the emergence of several issues related to literary translation and subtitling. All students were asked to apply interpersonal skills and through their response to the questions raised and the critique of their work, they showed that they possessed flexibility, adaptability, and tolerance. They also called upon empathy when some members had to involuntarily withdraw from the tasks undertaken due to the pandemic. All these important qualities were further enhanced by collaborative work.

Translation is the result of teamwork, and the sooner students learn about the various stages it goes through, from the commission of the work to the submission (publishing of the book or distribution of the subtitled program), the better equipped they will be for work postgraduation. Through interactive teamwork students internalize knowledge and learn how to learn. Providing students with the opportunity to work in teams for the purposes of the slam helped them gain insights into translation project management, workflows, and processes. Aiming to assist our students in developing self-confidence and, perhaps more importantly, self-awareness, we also asked them to reflect on the translation/subtitling process and the slam experience. Quite telling was the fact that students not only referred to the challenges faced,

\footnotetext{
${ }^{16}$ In the words of Maria González-Davies and Vanessa Enríquez-Raído, 'situated learning' is “a context-dependent approach to translator and interpreter training under which learners are exposed to real-life and/or highly simulated work environments and tasks, both inside and outside the classroom" $(2016,1)$. The aim of this approach is to help students develop critical thinking skills and act like professionals.
} 
sharing the rationale behind their decisions, but also expressed their understanding of the dynamic nature of languages and cultures and of translation itself. In the words of Don Kiraly, highly authentic translation situations "allow us to observe the interplay of authenticity, emerging autonomy and developing competence both within groups and individuals" (2005, 1110). Situated translation projects, like the online translation slam in discussion, can lead to the development of translator competence (Kiraly 2005, 1110; 2012a, 84). To this end, as translation scholars and researchers we will continue to work towards designing open syllabuses of literary and audiovisual translation courses as well as explore the possibilities of translator/subtitler training in an age characterized by the emphasis placed on professionalism in the translating industry. 
transLogos 2021 Vol 4 Issue 1

Gouleti, Katerina, and Vasiliki Misiou, pp. 1-25

Crossing Swords while Crossing Boundaries: Teaching

\section{References}

Amador Moreno, Carolina P., and Ana Nunes, eds. 2009. The Representation of the Spoken Mode in Fiction: How Authors Write How People Talk. Lewiston, New York: Edwin Mellen Press.

Amador Moreno, Carolina P., and Kevin McCafferty. 2011. "Fictionalising Orality: Introduction." In "Fictionalising Orality," edited by Carolina P. Amador Moreno and Kevin McCafferty. Special Issue, Sociolinguistic Studies 5 (1): 1-13. doi:10.1558/sols.v5i1.1.

Arnold, Jane, ed. 1999. Affect in Language Learning. Cambridge: Cambridge University Press.

Atwood, Margaret. 1985. The Handmaid's Tale. Toronto, Canada: McClelland and Stewart.

Baig, Mehroz. 2014. "Slam Poetry: A History." HuffPost. March 12. https://www.huffpost.com/entry/slam-poetry-a-history_b_4944799.

Bal, Mieke, and Joanne Morra. 2007. "Editorial: Acts of Translation." Journal of Visual Culture 6 (1): 5-11. https://journals.sagepub.com/doi/pdf/10.1177/1470412907076198.

Bassano, Sharron, and Mary Ann Christison. 1994. Community Spirit: A Practical Guide to Collaborative Language Learning. Burlingame, CA: Alta.

Bennett, Barrie, Carol Rolheiser-Bennett, and Laurie Stevahn. 1991. Cooperative Learning: Where Heart Meets Mind. Toronto: Educational Issues.

Benson, Phil, and Peter Voller, eds. 1997. Autonomy and Independence in Language Learning. New York: Longman.

Brown, George Isaac. 1971. Human Teaching for Human Learning: An Introduction to Confluent Education. New York: Viking Press.

Brumfit, Christopher J., and Keith Johnson, eds. 1979. The Communicative Approach to Language Teaching. Oxford: Oxford University Press.

Bühler, Karl. 1934. Sprachtheorie [Theory of language]. Oxford: Fischer.

Candlin, Christopher N. 1981. The Communicative Teaching of English: Principles and an Exercise Typology. Edited and translated by Christopher N. Candlin. Harlow, Essex: Longman.

Damon, Maria. 1998. "Was That 'Different,' 'Dissident' or 'Dissonant'? Poetry (n) the Public Spear: Slams, Open Readings, and Dissident Traditions.” In Close Listening: Poetry and the Performed Word, edited by Charles Bernstein, 324-342. Oxford: Oxford University Press. 
transLogos 2021 Vol 4 Issue 1

Gouleti, Katerina, and Vasiliki Misiou, pp. 1-25

Crossing Swords while Crossing Boundaries: Teaching

Translation through Intermedial Translation Slams

Díaz Cintas, Jorge, and Aline Remael. 2007. Audiovisual Translation: Subtitling. Manchester: St. Jerome.

Dicerto, Sara. 2018. Multimodal Pragmatics and Translation: A New Model for Source Text Analysis. Cham: Palgrave Macmillan.

Genette, Gérard. 1997. Paratexts: Thresholds of Interpretation. Translated by Jane E. Lewin. Cambridge: Cambridge University Press.

González Davies, Maria. 2002. "Humanising Translation Activities: Tackling a Secret Practice." Humanising Language Teaching 4 (4). http://old.hltmag.co.uk/jul02/mart2.htm.

- 2004. Multiple Voices in the Translation Classroom: Activities, Tasks and Projects. Amsterdam: John Benjamins.

González-Davies, Maria, and Vanessa Enríquez-Raído. 2016. "Situated Learning in Translator and Interpreter Training: Bridging Research and Good Practice." The Interpreter and Translator Trainer 10 (1): 1-11. doi:10.1080/1750399X.2016.1154339.

Gutteridge, Tim. 2018. "Ingredients for a Perfect Translation Slam.” Tim Gutteridge. October 9. http://timgutteridge.co.uk/ingredients-for-a-perfect-translation-slam/.

Hanvey, Robert. 1992. “Culture.” In The Tapestry of Language Learning: The Individual in the Communicative Classroom, edited by Robin C. Scarcella and Rebecca L. Oxford, 182192. Boston: Heinle and Heinle.

Holt, Daniel D., ed. 1993. Cooperative Learning: A Response to Linguistic and Cultural Diversity. McHenry, IL: Center for Applied Linguistics and Delta Systems.

House, Juliane. 2015. Translation Quality Assessment: Past and Present. London: Routledge.

Hurtado Albir, Amparo. 1995. "La didáctica de la traducción: Evolución y estado actual." [Translation teaching: Development and current situation.] In Perspectivas de la traducción inglés/español [Perspectives of English/Spanish translation], edited by Purificación Fernández Nistal and José María Bravo Gozalo, 49-74. Valladolid: ICE, Universidad de Valladolid.

Jakobson, Roman. 1959. “On Linguistic Aspects of Translation.” In On Translation, edited by Reuben Arthur Brower, 232-239. Cambridge, MA: Harvard University Press.

Jay, Timothy. 1992. Cursing in America: A Psycholinguistic Study of Dirty Language in the Courts, in the Movies, in the Schoolyards and on the Streets. Philadelphia: John Benjamins.

Kaindl, Klaus. 2012. "Multimodality and Translation." In The Routledge Handbook of Translation Studies, edited by Carmen Millán and Francesca Bartrina, 257-269. London: Routledge. 
transLogos 2021 Vol 4 Issue 1

Gouleti, Katerina, and Vasiliki Misiou, pp. 1-25

Kelly, Dorothy. 2005. A Handbook for Translator Trainers: A Guide to Reflective Practice. Manchester: St. Jerome.

Kiraly, Don. 2000. A Social Constructivist Approach to Translator Education: Empowerment from Theory to Practice. Manchester: St. Jerome.

— 2005. "Project-Based Learning: A Case for Situated Translation." Meta 50 (4): 10981111. doi:10.7202/012063ar.

. 2012a. "Growing a Project-Based Translation Pedagogy: A Fractal Perspective." Meta 57 (1): 82-95. doi:10.7202/1012742ar.

- 2012b. "Skopos Theory Goes to Paris: Purposeful Translation and Emergent Translation Projects." In "sed sensum exprimere de sensu: In Memoriam Hans J. Vermeer," edited by Hanna Risku, Christina Schäffner, and Jürgen F. Schopp. Special Issue, $m$ Tm 4:119-144. http://www.mtmjournal.gr/datafiles/files/MTM_4.pdf.

Kress, Gunther. 2003. Literacy in the New Media Age. London: Routledge.

Kress, Gunther, and Theo van Leeuwen. (1996) 2006. Reading Images: The Grammar of Visual Design. London: Routledge.

- 2001. Multimodal Discourse: The Modes and Media of Contemporary Communication. London: Arnold.

Kussmaul, Paul. 1995. Training the Translator. Amsterdam: John Benjamins.

Marco, Josep. 2016. "On the Margins of the Profession: The Work Placement as a Site for the Literary Translator Trainee's Legitimate Peripheral Participation." The Interpreter and Translator Trainer 10 (1): 29-43. doi:10.1080/1750399X.2016.1154341.

McEnery, Tony. 2006. Swearing in English: Bad Language, Purity and Power from 1586 to the Present. London: Routledge.

Misiou, Vasiliki. 2020. "Navigating a Multisemiotic Labyrinth: Reflections on the Translation of Mark Z. Danielewski's House of Leaves." Punctum. International Journal of Semiotics 6 (1): 243-264. doi:10.18680/hss.2020.0012.

Moskowitz, Gertrude. 1978. Caring and Sharing in the Language Class: A Sourcebook on Humanistic Techniques. Rowley, Mass.: Newbury House.

Nord, Christiane. 1991. Text Analysis in Translation: Theory, Methodology, and Didactic Application of a Model for Translation-Oriented Text Analysis. Amsterdam: Rodopi.

Nunan, David. 1993. Syllabus Design. Oxford: Oxford University Press.

Olohan, Maeve. 2020. Translation and Practice Theory. London: Routledge. 
transLogos 2021 Vol 4 Issue 1

Gouleti, Katerina, and Vasiliki Misiou, pp. 1-25

Crossing Swords while Crossing Boundaries: Teaching

Translation through Intermedial Translation Slams

O’Sullivan, Carol, and Caterina Jeffcote, eds. 2013. "Translating Multimodalities.” Special issue, JoSTrans The Journal of Specialised Translation, no. 20. https://www.jostrans.org/issue20/issue20_toc.php.

Parks, Tim. 2017. "Gained in Translation." December 9. The New York Review. https://www.nybooks.com/daily/2017/12/09/gained-in-translation/.

Peter, Constantine. 2020. "Literary Translation Pedagogy in the United States: New Trends." Translation Review 106 (1): 10-14. doi:10.1080/07374836.2019.1625833.

Prince, Michael J., and Richard M. Felder. 2006. "Inductive Teaching and Learning Methods: Definitions, Comparisons, and Research Bases.” Journal of Engineering Education 95 (2): 123-138. doi:10.1002/j.2168-9830.2006.tb00884.x.

Reiss, Katharina. (1977) 1989. "Text Types, Translation Types and Translation Assessment." Translated by Andrew Chesterman. In Readings in Translation Theory, edited by Andrew Chesterman, 105-115. Helsinki: Finn Lectura.

Richards, Jack C., and Theodore S. Rodgers. 2001. Approaches and Methods in Language Teaching. Cambridge: Cambridge University Press.

Scott, Clive. 2010. "Intermediality and Synesthesia: Literary Translation as Centrifugal Practice." Art in Translation 2 (2): 153-169. doi:10.2752/175613110X12706508989415.

Slavin, Robert E. 1990. Cooperative Learning: Theory, Research, and Practice. Englewood Cliffs: Prentice Hall.

Spears, Richard A. 1998. NTC's Super-Mini Forbidden American English. Chicago: NTC Publishing Group.

Thomas, Jenny. 1995. Meaning in Interaction: An Introduction to Pragmatics. London: Longman.

Van Leeuwen, Theo. 2005. Introducing Social Semiotics. London: Routledge.

Varney, Jennifer. 2009. "From Hermeneutics to the Translation Classroom: A Social Constructivist Approach to Effective Learning." Translation \& Interpreting 1 (1): $27-$ 43. http://www.trans-int.org/index.php/transint/article/view/24/39.

Williams, Marion. 1999. "Learning Teaching: A Social Constructivist Approach.” In Theory in Language Teacher Education, edited by Hugh Trappes-Lomax and Ian McGrath, 1120. Harlow: Longman. 